\title{
Effect of Pouring Temperature and Water Cooling on the Thixotropic Semi-solid Microstructure of A319 Aluminium Cast Alloy
}

\author{
Iman Sallah-ElDeen El-Mahallawi ${ }^{a}$,Tamer Samir Mahmoud ${ }^{\text {* }}$, \\ Ahmed Mohamed Gaafer ${ }^{b}$, Fouad Helmi Mahmoud \\ ${ }^{a}$ Mining, Petroleum and Metallurgical Department, Faculty of Engineering, Cairo University, Giza, Egypt \\ ${ }^{b}$ Mechanical Engineering Department, Shoubra Faculty of Engineering, Benha University, Cairo, Egypt
}

Received: June 20, 2014; Revised: January 23, 2015

\begin{abstract}
The cooling slope (CS) casting is the simplest and cheapest technique for producing feedstock materials with non-dendritic microstructure. Such materials are required for semi-solid metal (SSM) processing methods such as thixoforming. In the present investigation, the effect of the pouring temperature and the water cooling on the thixotropic microstructure of commercial A319 Al-Si cast alloy was studied. The results showed that increasing the pouring temperature slightly reduces the bulk porosity of the CS ingots. The ingots poured with water-cooling exhibited slightly lower porosity content than those poured with without water-cooling. Generally, the primary $\alpha$-Al grains exhibited higher shape factor near the edge of ingot than the middle and center. Ingots poured with water-cooling exhibited lower grain size and shape factor than those poured without water-cooling. Increasing the pouring temperature increases the size $\alpha$-Al grains.
\end{abstract}

Keywords: cooling slope casing, microstructure, thixotropic, aluminium alloys

\section{Introduction}

Thixoforming and thixocasting are semi-solid processing (SSP) technologies combining the near-net-shape capabilities of die-casting and mechanical properties of forging ${ }^{1,2}$. Parts produced by thixoforming techniques are reported to have substantially higher quality than die-castings and lower cost than forgings ${ }^{3,4}$. However, a special ingot with thixotropic (non-dendritic) microstructure is required for thixoforming. Therefore, ingots that are not made especially for thixoforming, i.e. not possessing the appropriate microstructures, cannot be used. Several commercial aluminium alloys such as A356 and A357 (Al-Si-Mg) are used as thixoforming materials $\mathrm{s}^{5-7}$. These alloys provide high fluidity and good castability. The A356 and A357 alloys are widely used in fabrication of automobile components.

Cooling slope (CS) casting is one of the simplest and cheapest techniques used to produce ingots for thixocasting and rehocasting ${ }^{1,3}$. In this technique, molten alloy with a superheat temperature is poured on an inclined plate. Solid nucleuses are formed because of the contact between the melt and the slope plate, detached from the surface because of the applied shear stress due to gravity force and melt flow. Ingots produced from CS casting have thixotropic microstructure required for thixoforming. In CS casting, various parameters such as superheat (pouring) temperature, length, angle, vibration, water-cooling, inclined plate and mold materials can affect the final microstructure ${ }^{1,3,8}$. The effect of such parameters on the microstructural characteristics of both

*e-mail: tsamir@benha-univ.edu.eg
A356 and A357 Al alloys was extensively studied ${ }^{1,3,8-11}$. In contrast, there is a lack of investigations studying the effect of CS casting process parameters on other cast $\mathrm{Al}$ alloys such as A319 and A390 alloys ${ }^{12,13}$. This lack of data is more important when it is considered that these alloys have wide use in automotive industry. The A319 (Al-Si-Cu) cast $\mathrm{Al}$ alloy have a wide solidification range which makes it suitable for $\mathrm{SSP}^{14-18}$. The A319 alloy exhibits good castability, weldability and corrosion resistance. Moreover, the mechanical properties of the A319 alloy are not largely affected by fluctuations in impurity content. Typical uses of the A319 alloy are in permanent mold casting with applications including water-cooled cylinder heads, rear axle housings and engine parts. Accordingly, the aim of the present investigation is to investigate the effect of pouring temperature and water-cooling on the microstructural characteristics of A319 aluminum alloy ingots produced by cooling slope casting.

\section{Experimental Procedures}

In this study, commercial A319 Al-Si-Cu cast Al alloy was used. The composition of the A319 alloy is given in Table 1. To determine the solidus and liquidus temperatures, also the variation of melt liquid percent with temperature, the differential scanning calorimetric (DSC) analysis was carried out. The DSC experiments were carried during heating with a heating rate of $5^{\circ} \mathrm{C} / \mathrm{min}$. Figure 1 shows the resulted DSC curve of the A319 alloy. The figure shows 
Table 1. Chemical composition of A319 aluminum alloys (wt.-\%).

\begin{tabular}{cccccccccc}
\hline Alloy & $\mathbf{S i}$ & $\mathbf{F e}$ & $\mathbf{C u}$ & $\mathbf{M g}$ & $\mathbf{M n}$ & $\mathbf{N i}$ & $\mathbf{Z n}$ & $\mathbf{T i}$ & Al \\
\hline A319 & 6.48 & 0.25 & 3.00 & 0.002 & 0.003 & 0.004 & 0.013 & 0.009 & Bal. \\
\hline
\end{tabular}

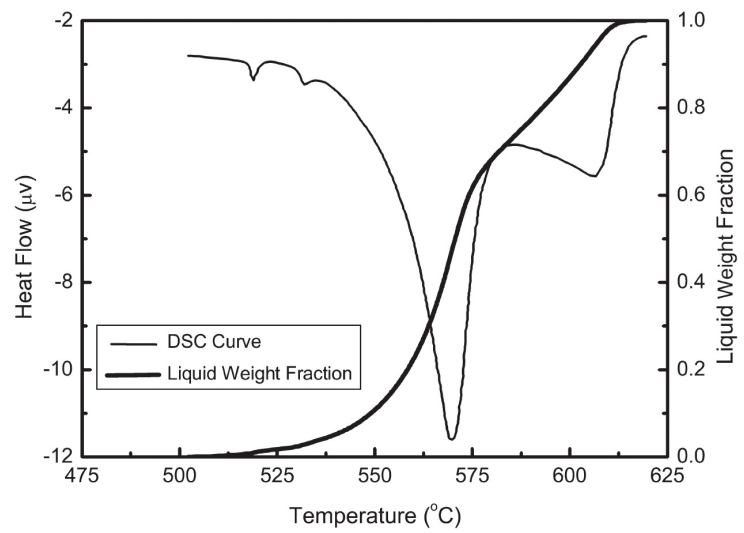

Figure 1. DSC and liquid weight fraction versus temperature curves for A319 alloy.

also the curve representing the variation of liquid weight fraction with the temperature. This curve was obtained after integrating the area under DSC curve. Figure 1 shows that the solidus and liquidus temperatures of the A319 alloys are $\sim 507^{\circ} \mathrm{C}$ and $\sim 611^{\circ} \mathrm{C}$, respectively.

The CS casting process was carried as follows: About $1.5 \mathrm{~kg}$ of the A319 alloy was melted in graphite crucible in an electric resistance furnace at $680^{\circ} \mathrm{C}$. The molten metal was then allowed to cool down to the specified pouring temperature (typically, $600^{\circ} \mathrm{C}, 620^{\circ} \mathrm{C}$ and $640^{\circ} \mathrm{C}$ ). The melt was then continuously poured on a plate of $100 \mathrm{~mm}$ wide and collected into a steel mould. The steel mould had a diameter of $50 \mathrm{~mm}$ and height of $160 \mathrm{~mm}$ with a draft angle of $2^{\circ}$ for easy removal of the solidified ingot. The plate is made from mild steel and coated with a thin layer of hard Chromium to prevent adhesion between the molten metal and the plate. The cooling plate was fixed at $60^{\circ}$ with respect to the horizontal plane and was cooled with water circulation underneath. Figure 2 shows a schematic illustration of the cooling slope process. Pouring was carried out with and without water cooling circulation. The flow length of the molten metal over the plate was also fixed at $500 \mathrm{~mm}$. The water cooling circulation system consists of a water tank, a water pump and a thermometer which was located in the water tank. The water was pumped from the bottom to the top of the plate with a flow rate of $20 \mathrm{lit} / \mathrm{min}$ and a temperature of about $20^{\circ} \mathrm{C}$.

Figure 3 shows a photograph of a sample ingot produced from the CS casting process. The upper part of the ingot with $35 \mathrm{~mm}$ height containing the shrinkage cavity was removed from the ingot. The remained part of the ingot was cut longitudinally into two parts and prepared for macrostructual examinations. Transverse metallographic samples were cut from the top and bottom of the remained ingots and then ground, and polished for microstructural examinations (see Figure 3). Macroetching was carried out

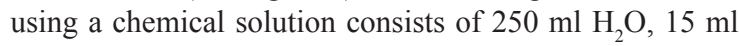
$\mathrm{HNO}_{3}, 15 \mathrm{ml} \mathrm{HF}$ and $45 \mathrm{ml} \mathrm{HCl}$ for $10-15$ seconds at ambient temperature. Microetching was carried out using a chemical solution consists of $0.5 \mathrm{ml} \mathrm{HF} 40 \%+100 \mathrm{ml}$ $\mathrm{H}_{2} \mathrm{O}$ for 5-60 s at an ambient temperature.

The bulk porosity of the ingots produced from the CS casting were measured using water displacement technique (Archimedes principle). Analysis on the size and shape factor $(\mathrm{SF})$ of the primary $\alpha$-Al grains were carried out using image-analyzing techniques. The average size of $\alpha-\mathrm{Al}$ grains were measured by the linear intercept method according to the ASTM-E112-96 ${ }^{19}$. The shape factor was determined from the following equation ${ }^{11}$ :

$\mathrm{SF}=\mathrm{P}^{2} / 4 \pi \mathrm{A}$

where $P$ is the perimeter and $A$ is the area of $\alpha-\mathrm{Al}$ grain. For a perfect circle, the shape factor would be one.

\section{Results and Discussion}

\subsection{The porosity of CS ingots}

Figure 4 shows typical macrograph of longitudinal cross-section of ingots produced using CS casting at different pouring temperatures and with and without water-cooling. It has been observed that large pores were located at the upper part of the CS cast ingot. Such pores were only observed for CS cast ingots poured at $600^{\circ} \mathrm{C}$ (i.e. the lowest pouring temperature). However, the size and quantity of the pores were reduced by using the water-cooling (compare between Figure $4 \mathrm{a}$ and $4 \mathrm{~b}$ ). Ingots poured at higher pouring temperatures than $600{ }^{\circ} \mathrm{C}$ (i.e. $620^{\circ} \mathrm{C}$ and $640^{\circ} \mathrm{C}$ ) did not show any large pores all over the ingot.

Figure 5 shows the variation of the bulk porosity of the CS cast ingots with the pouring temperatures. It has been found that the bulk porosity of the CS cast ingots varies between 3.13 vol.- $\%$ and 3.75 vol.- $\%$. At pouring temperatures of 600 and $620{ }^{\circ} \mathrm{C}$, the ingots poured with water-cooling exhibited slightly lower porosity content than those poured with without water-cooling. For example, at constant pouring temperature of $600{ }^{\circ} \mathrm{C}$, the $\mathrm{CS}$ cast ingots produced with and without water-cooling showed bulk porosity of 3.54 vol.-\% and 3.75 vol.-\%, respectively. However, at the highest pouring temperature (i.e. $640{ }^{\circ} \mathrm{C}$ ), the bulk porosity contents of CS cast ingots produced with and without water cooling were practically the same as shown in Figure 5. It has been found also that increasing the pouring temperature slightly reduces the bulk porosity of the CS cast ingots. For example, increasing the pouring temperature from $600{ }^{\circ} \mathrm{C}$ to $640{ }^{\circ} \mathrm{C}$ reduced the bulk porosity of the CS cast ingots from 3.75 vol.- $\%$ to 3.13 vol.- $\%$ for the ingots poured without water-cooling. 


\subsection{The microstructure of CS cast ingots}

The microstructure of the conventionally cast A319 ingot is shown in Figure 6. The figure shows that the microstructure contains coarse dendrites of primary $\alpha$-Al phase. It has been found that the dendrites of $\alpha$-Al phase have size more than $350 \mu \mathrm{m}$ while the average secondary dendrite arm spacing (SDAS) of $\alpha$-Al phase in the conventionally as-cast sample was $\sim 18 \mu \mathrm{m}$. Figures 7 and 8 shows typical microstructures of the CS cast ingots produced using several processing conditions of pouring temperatures and water cooling. The microstructure of the CS ingot is significantly different from the conventionally cast A319 ingot shown in Figure 6. The CS cast ingots showed non-dendritic microstructure of the primary $\alpha$-Al phase.

Figure 9 shows the variation of the shape factor (SF) of primary $\alpha$-Al grains with the position at the transverse section of the ingots. It can be seen that the primary $\alpha-\mathrm{Al}$ grains have generally higher shape factor near the edge of ingot than the middle and center. For example, ingots poured at $600{ }^{\circ} \mathrm{C}$ without water-cooling, the $\alpha$-Al grains showed shape factors of 1.75 and 2.21 at the center and radius positions of the ingots, respectively. This observation was noticed for ingots poured with and without water-cooling. The water-cooled CS cast ingots exhibited lower shape factor when compared with those casted without water-cooling.

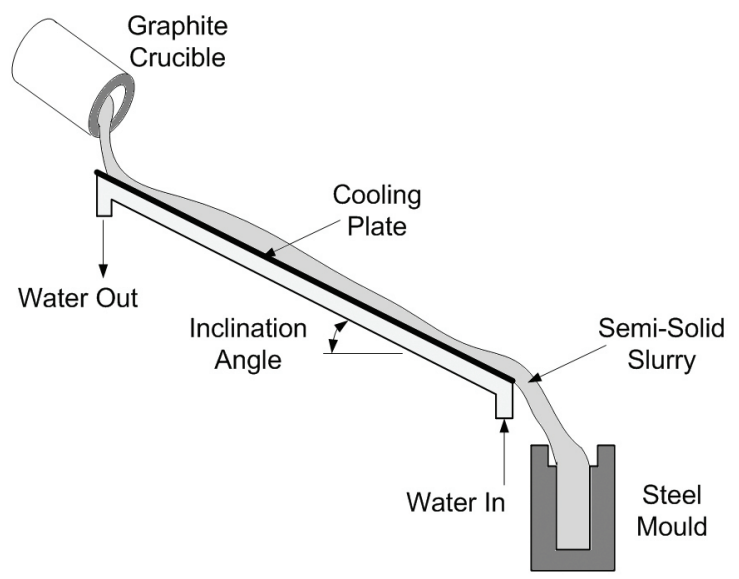

Figure 2. A schematic illustration cooling slope casting apparatus used in the present work.

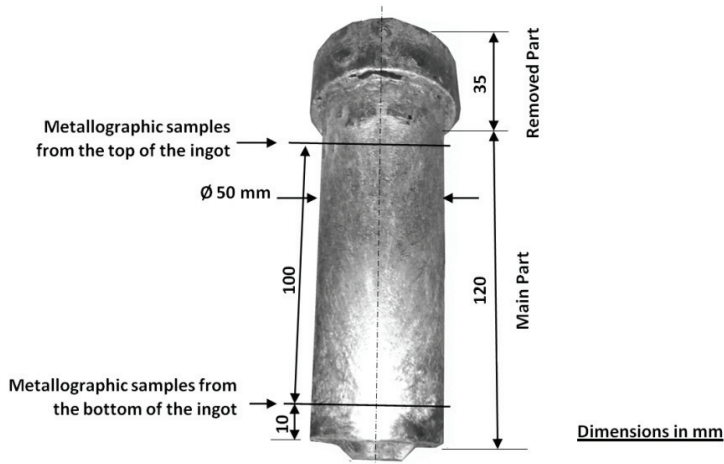

Figure 3. A photograph of the produced ingot showing its main dimensions and the position of metallographic samples.
For example, at $620^{\circ} \mathrm{C}$, ingots poured with- and without water-cooling exhibited shape factors of 1.66 and 1.85, respectively, at the center of the ingots. The results showed also that increasing the pouring temperature increasing the shape factor of the $\alpha$-Al grains. This observation was noticed for both conditions of cooling (i.e. with and without water-cooling). For example, the center of CS cast ingots poured with water-cooling exhibited shape factors of 1.47, 1.663 and 1.81 at $600{ }^{\circ} \mathrm{C}, 620^{\circ} \mathrm{C}$ and $640{ }^{\circ} \mathrm{C}$, respectively.

Figure 10 shows the effect of pouring temperature on the size of primary $\alpha-\mathrm{Al}$ grains. The results revealed that the primary $\alpha$-Al grains lower average grain size near the edge of ingot than the middle and center. Such observation was noticed for CS cast ingots poured with and without water-cooling. For example, ingots poured at $600^{\circ} \mathrm{C}$ without water-cooling, the $\alpha$-Al grains showed average size of 33 , 28 and $22 \mu \mathrm{m}$ at the center, middle and radius positions of the ingots, respectively. The CS cast ingots poured with water-cooling exhibited slightly lower average grain size of the primary $\alpha-\mathrm{Al}$ grains than those poured without water-cooling. For example, ingots poured at $620^{\circ} \mathrm{C}$ with and without water-cooling exhibited average size of $\alpha-\mathrm{Al}$ grains of 37 and $35 \mu \mathrm{m}$ at the central position of the ingots, respectively. It is clear from Figure 10 that increasing the pouring temperature increases the average size of the

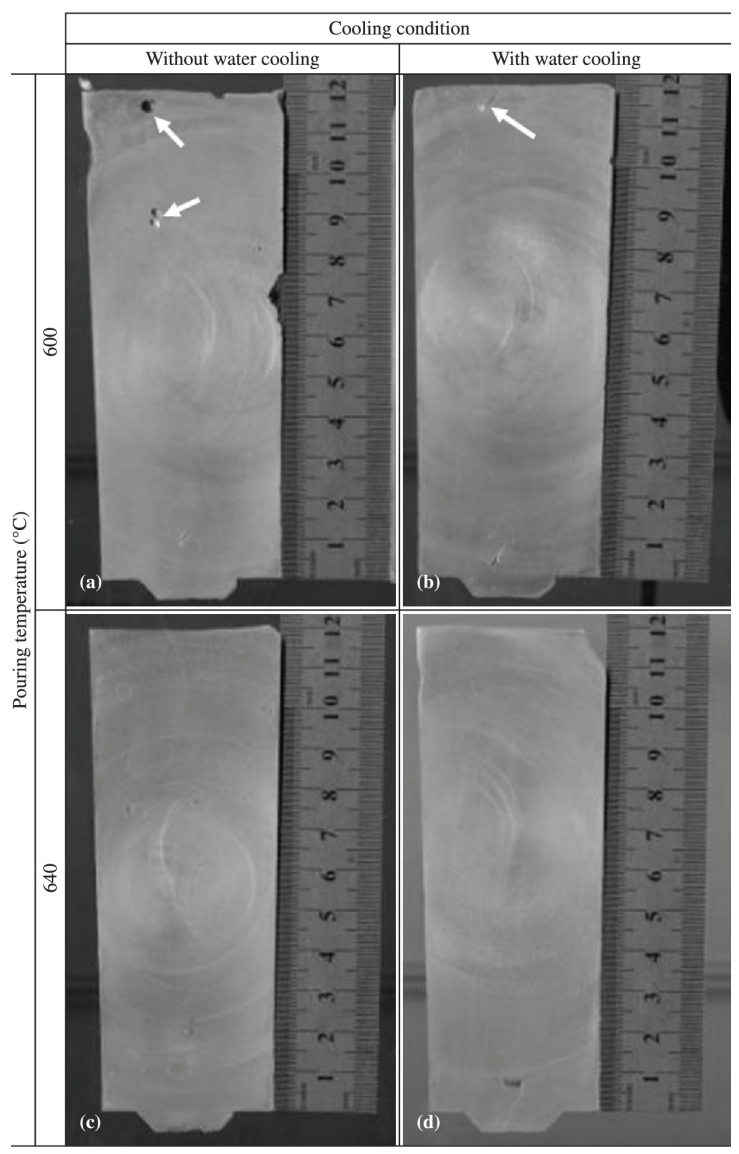

Figure 4. Typical macrograph of the longitudinal cross-section of ingots produced using CS casting with and without water-cooling and different pouring temperatures. 


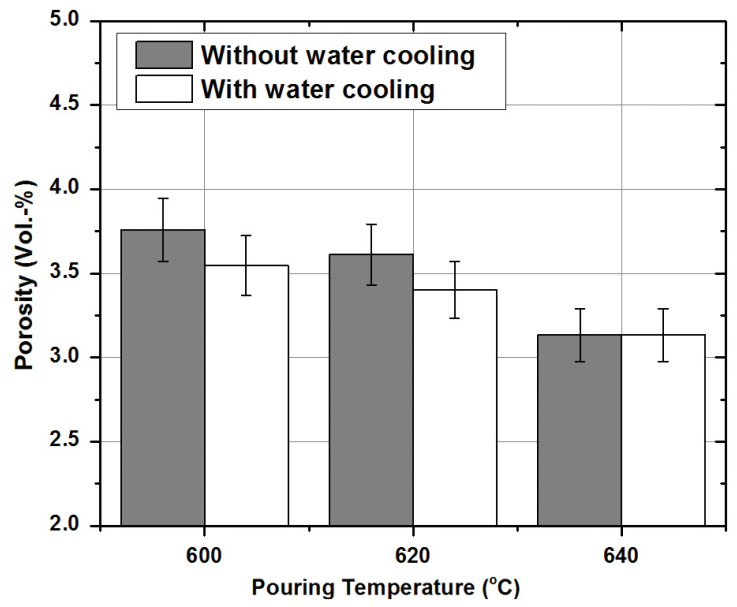

Figure 5. Variation of the bulk porosity of the CS cast ingots with the pouring temperatures.

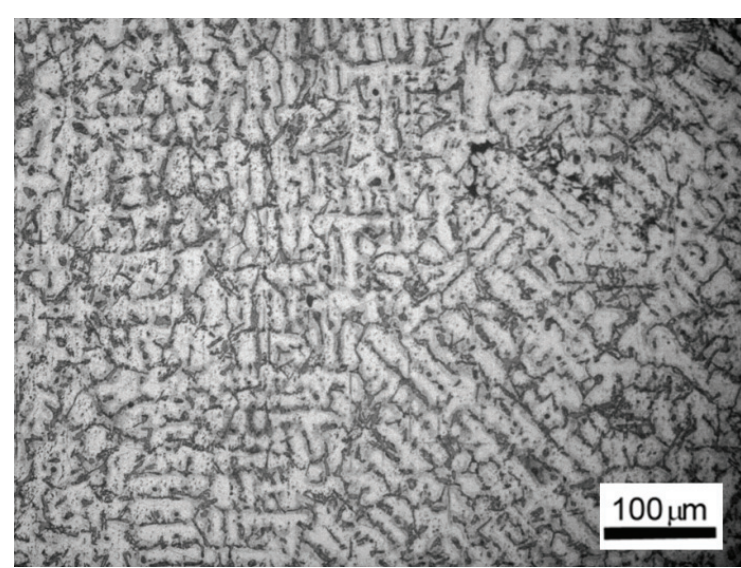

Figure 6. Microstructures of the conventionally cast A319 Al-Si alloy.

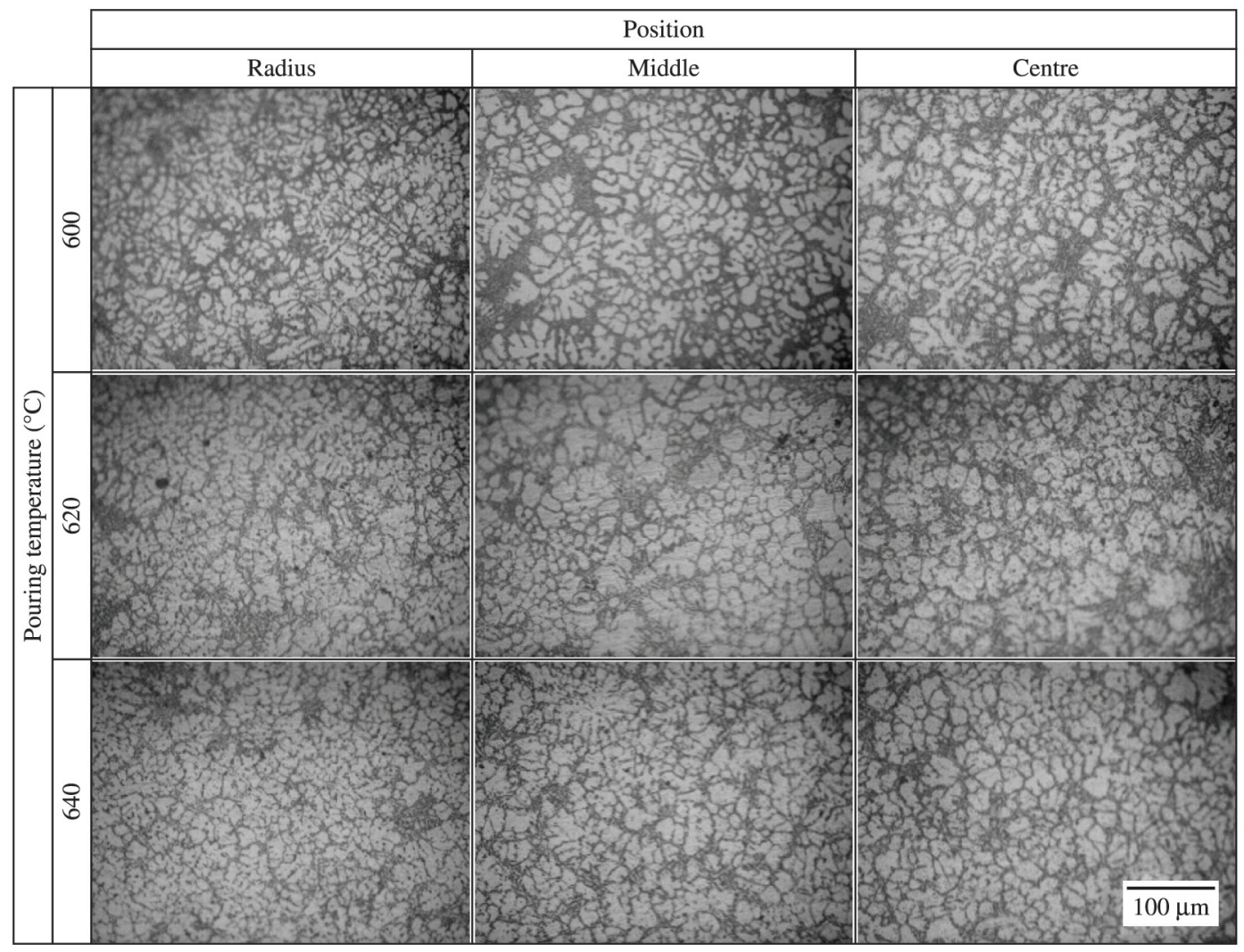

Figure 7. Microstructures of CS cast ingot without water-cooling.

primary $\alpha$-Al grains. For example, the center of CS cast ingots poured with water-cooling exhibited average size of the primary $\alpha$-Al grains of 30,35 and $37 \mu \mathrm{m}$ at $600{ }^{\circ} \mathrm{C}$, $620^{\circ} \mathrm{C}$ and $640^{\circ} \mathrm{C}$, respectively.

In the present investigation, the introduction of water-cooling reduced the size of the primary $\alpha$-Al grains of the CS cast ingots. It is believed that the introduction of water-cooling has caused the molten metal to cool faster while flowing down the cooling slope. In solidification process, the nucleation and spherodisation can be influenced by cooling rate ${ }^{11}$. Increasing the cooling rate can promote the nucleation rate. The change of the nucleation rate influences the grain size and the shape factor of the primary $\alpha$-Al grains. In the case of pouring without water-cooling, the number of crystals nucleated and detached from the surface of the cooling plate was insufficient to produce fine and spheroidal primary crystals. The introduction to water-cooling leads to higher fractional solidification on the cooling 


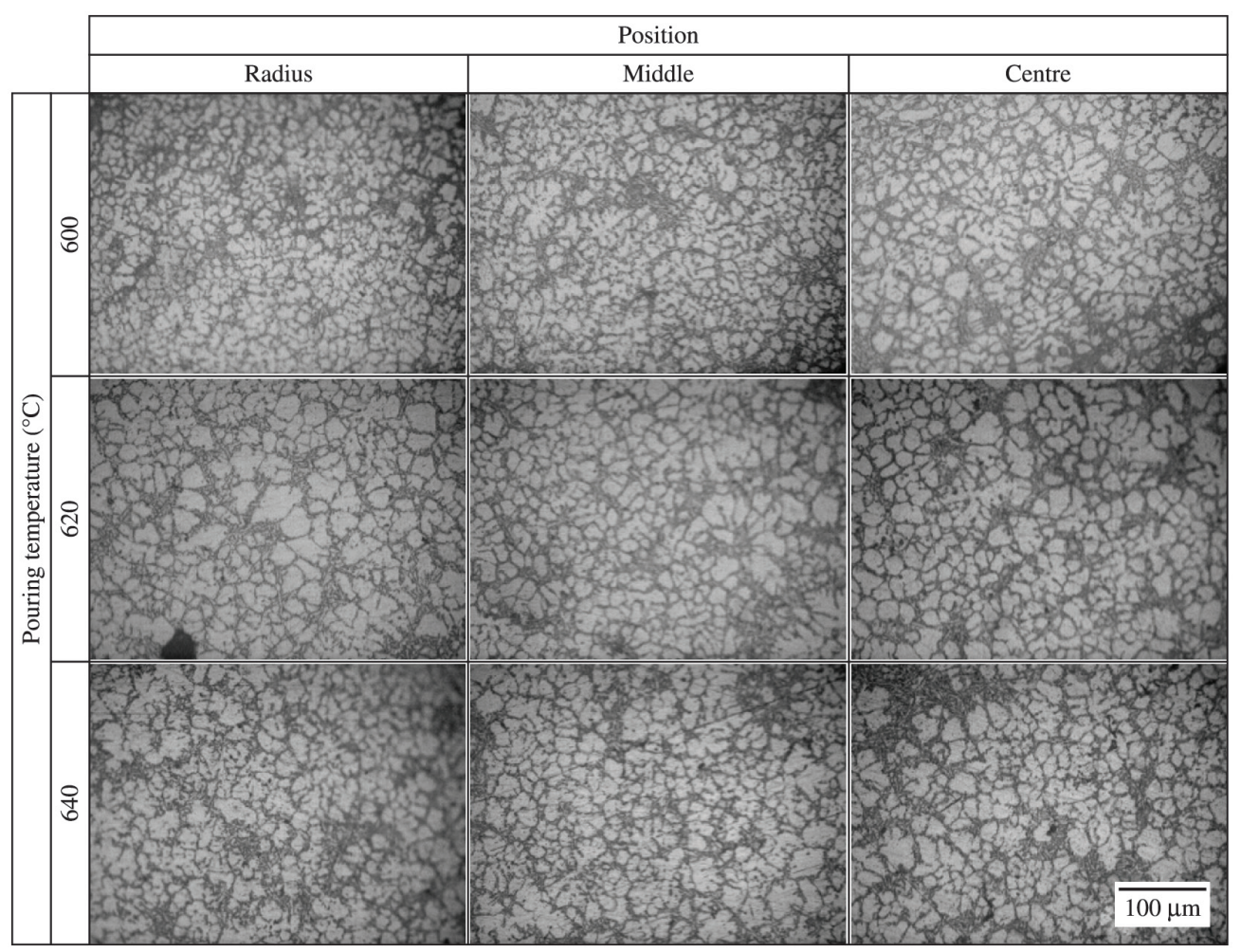

Figure 8. Microstructures of CS cast ingot with water-cooling.
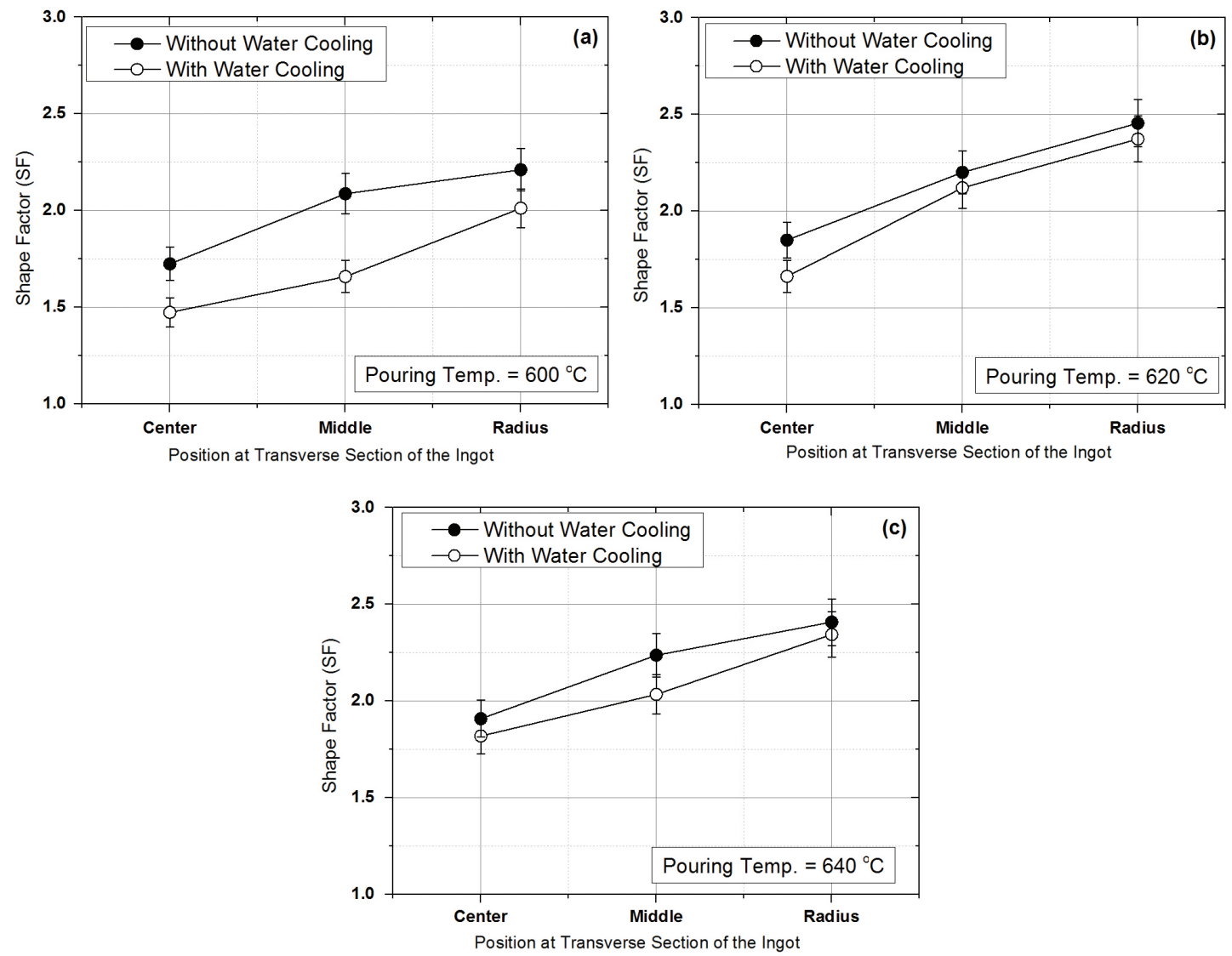

Figure 9. Variation of the shape factor of primary $\alpha$-Al grains with the position at the transverse section of the ingots. 

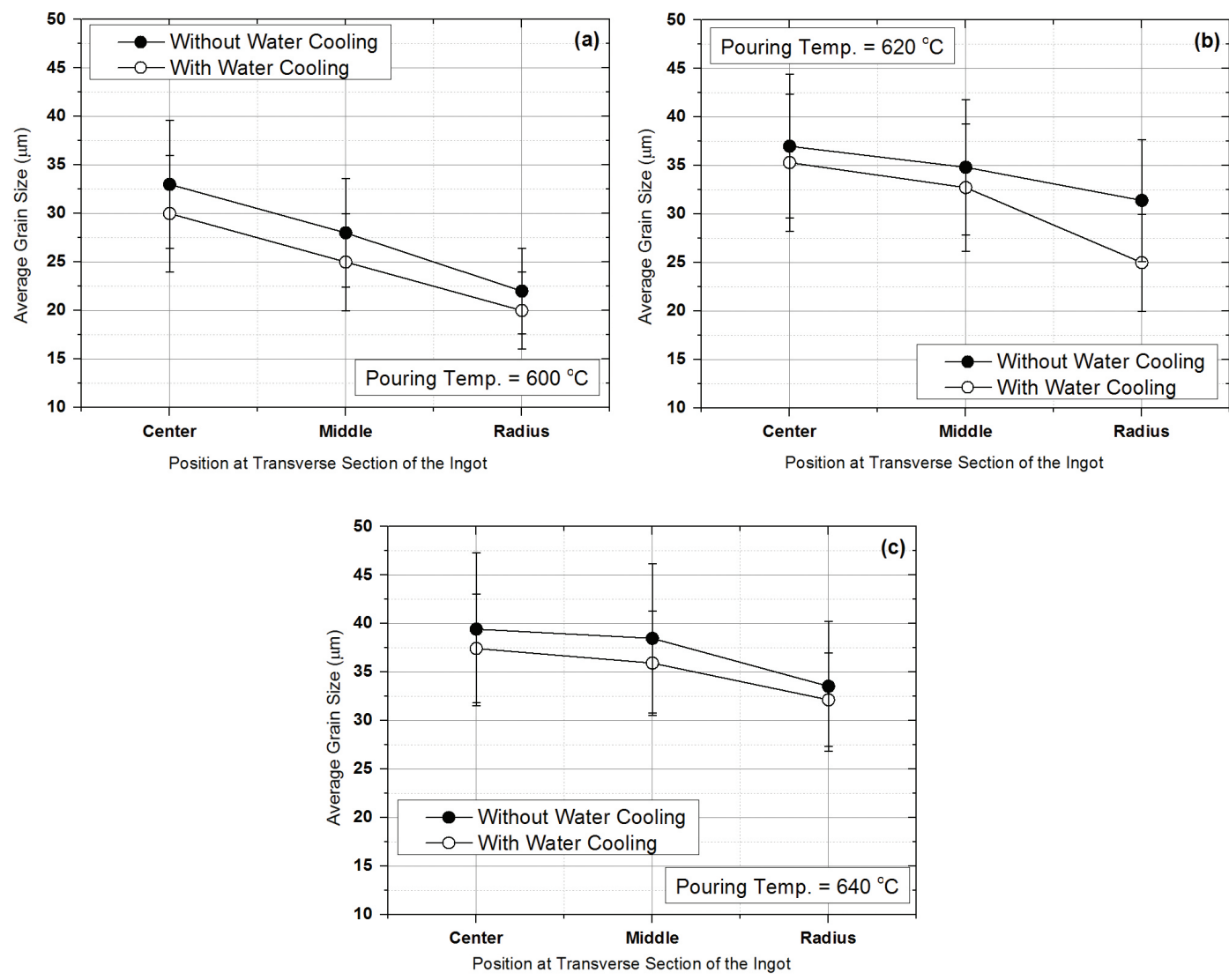

Figure 10. Variation of the grain size of primary $\alpha-\mathrm{Al}$ grains with the position at the transverse section of the ingots.

plate and increase the rate of nucleation and detachment of the $\alpha$-Al crystals resulted in finer and non-dendritic primary $\alpha$-Al grains. High pouring temperature leads to decrease in nucleation, remelting the primary crystals and undesired grain growth. Low pouring temperature causes rapid solidification of melt on the slope and thus dendritic solidification.

\section{Conclusions}

Based on the results presented, the following conclusions can be drawn:

1. The cooling slope (CS) cast ingots poured with water-cooling exhibited slightly lower bulk porosity than those poured without water-cooling. Increasing the pouring temperature slightly reduces the bulk porosity of the CS cast ingots.

\section{References}

1. Taghavi F and Ghassemi A. Study on the effects of the length and angle of inclined plate on the thixotropic microstructure of A356 aluminum alloy. Technical Report, Materials and Design. 2009; 30(5):1762-1767. http://dx.doi.org/10.1016/j. matdes.2008.07.022.

2. Kang CG, Seo PK and Lim MD. Rheo and thixo die casting for automobile suspension parts. In: Proceedings of the 8th
2. The water-cooled CS cast ingots exhibited lower shape factor when compared with those cast without water-cooling. Increasing the pouring temperature increases the shape factor of the $\alpha$-Al grains.

3. The CS cast ingots poured with water-cooling exhibited slightly lower average grain size of the primary $\alpha$-Al grains than those poured without water-cooling. Increasing the pouring temperature increases the average size of the primary $\alpha-\mathrm{Al}$ grains.

\section{Acknowledgments}

The authors are thankful to Benha University - Shoubra Faculty of Engineering for providing financial support and facilities for carrying out this work.

International Conference on Semi-solid Processing of Alloys and Composites; Cyprus; 2004.

3. Haga T, Nakamura R, Tago R and Watari H. Effects of casting factors of cooling slope on semisolid condition. Trans. Nonferrous Met. Soc. China. 2010; 20:s968-s972. http:// dx.doi.org/10.1016/S1003-6326(10)60615-2.

4. Kapranos P, Kirkwood DH, Atkinson HV, Rheinlander JT, Bentzen JJ, Toft PT, et al. Thixoforming of an automotive part in A390 hypereutectic A1-Si alloy. Journal of Materials 
Processing Technology. 2003; 135(2-3):271-277. http://dx.doi. org/10.1016/S0924-0136(02)00857-9.

5. Paes M and Zoqui EJ. Semi-solid behavior of new Al-Si-Mg alloys for thixoforming. Materials Science and Engineering A. 2005; 406(1-2):63-73. http://dx.doi.org/10.1016/j. msea.2005.07.018.

6. de Freitas E, Ferrante M, Silva VF, Bose Filho W and Spinelli D. Thixoextrusion of an A356 alloy: microstructural studies and high temperature fatigue behaviour. Journal of Materials Processing Technology. 2004; 155-156:1629-1633. http:// dx.doi.org/10.1016/j.jmatprotec.2004.04.314.

7. Kapranos P, Ward PJ, Atkinson HV and Kirkwood DH. Near net shaping by semi-solid metal processing. Materials \& Design. 2000; 21(4):387-394. http://dx.doi.org/10.1016/S02613069(99)00077-1.

8. Birol Y. A357 thixoforming feedstock produced by cooling slope casting. Journal of Materials Processing Technology. 2007; 186(1-3):94-101. http://dx.doi.org/10.1016/j. jmatprotec.2006.12.021.

9. Legoretta EC, Atkinson HV and Jones H. Cooling slope casting to obtain thixotropic feedstock II: observations with A356 alloy. Journal of Materials Science. 2008; 43(16):5456-5469. http:// dx.doi.org/10.1007/s10853-008-2829-1.

10. Taghavi F, Saghafian H and Kharrazi YHK. Study on the ability of mechanical vibration for the production of thixotropic microstructure in A356 aluminium alloy. Materials \& Design. 2009; 30(1):115-121. http://dx.doi.org/10.1016/j. matdes.2008.04.034.

11. Budiman H, Omar MZ, Jalar A and Jaharah AG. Effect of Water Cooling on the Production of Al-Si Thixotropic Feedstock by Cooling Slope Casting. European Journal of Scientific Research. 2009; 32(2):158-166.
12. Birol Y. Cooling slope casting and thixoforming of hypereutectic A390 alloy. Journal of Materials Processing Technology. 2008:207(1-3):200-203.

13. Cerri E, Evangelista E, Spigarelli S, Cavaliere P and DeRiccardis F. Effects of thermal treatments on microstructure and mechanical properties in a thixocast 319 aluminum alloy. Materials Science and Engineering A. 2000; 284(1-2):254-260. http://dx.doi.org/10.1016/S0921-5093(00)00748-6.

14. Salleh MS, Omar MZ, Syarif J, Mohammed MN. An overview of semisolid processing of aluminium alloys. ISRN Materials Science. 2013; 2013:1-9. http://dx.doi. org/10.1155/2013/679820.

15. Atkinson HV. Alloys for semi-solid processing. Solid State Rhenomena. 2012; 192-193:16-27. http://dx.doi.org/10.4028/ www.scientific.net/SSP.192-193.16.

16. Salleh MS, Omar MZ, Syarif J and Mohammed MN. Thermodynamic Modelling on the Mutual Effect of Copper, Manganese and Iron Addition in Al-Si-Cu For Semisolid Processing. Journal of Asian Scientific Research. 2012; 2(11):614-619.

17. Robles Hernández FC and Sokolowski JH. Effects and online prediction of electromagnetic stirring on microstructure refinement of the 319 Al-Si hypoeutectic alloy. Journal of Alloys and Compounds. 2009; 480(2):416-421. http://dx.doi. org/10.1016/j.jallcom.2009.02.109.

18. Cavaliere P, Cerri E and Leo P. Effect of heat treatments on mechanical properties and damage evolution of thixoformed aluminium alloys. Materials Characterization. 2005; 55(1):3542. http://dx.doi.org/10.1016/j.matchar.2005.02.006.

19. American Society for Testing and Materials -ASTM. E112-96: Standard test methods for determining average grain size. West Conshohocken; 2004. 